\title{
Hot Topic: Fatty Acid and Conjugated Linoleic Acid (CLA) Isomer Composition of Commercial CLA-Fortified Dairy Products: Evaluation After Processing and Storage
}

\author{
L. M. Rodríguez-Alcalá and J. Fontecha ${ }^{1}$ \\ Department of Dairy Products, Instituto del Frío (CSIC), José Antonio Novais 10, Ciudad Universitaria s/n, 28040 Madrid, Spain
}

\begin{abstract}
Conjugated linoleic acid (CLA) exerts a strong positive influence on human health but intake of these fatty acids is typically too low, and increased consumption of CLA is recommended. A good way to raise the CLA content in the diet without a radical change in eating habits seems to be the enrichment of commonly consumed food products with CLA supplements. This study analyzed the total fatty acid content and the CLA isomer composition of 6 commercially available CLA-fortified dairy products during processing and $10 \mathrm{wk}$ of refrigerated storage. Research was carried out by combining gas chromatography and silver-ion HPLC. The tested samples were a CLA oil supplement, and several skim milk dairy products fortified with the supplement (milk, milk powder, fermented milk, yogurt, fresh cheese, and milk-juice blend). The CLA oil supplement was added such that the consumer received $2.4 \mathrm{~g} / \mathrm{d}$ of CLA by consuming 2 servings. The predominant isomers present, C18:2 cis-9, trans-11 CLA and C18:2 cis10 , trans-12 CLA, were in at a similar ratio, which ranged from 0.97 to 1.05 . These major isomers were not significantly affected by processing but a decrease in total CLA in fresh cheese samples was detected after 10 wk of refrigerated storage. Refrigerated storage and thermal treatment resulted in significant decreases or disappearance of some of the minor CLA isomers and a significant increase of trans, trans isomers from both cis, trans, trans, cis, and cis, cis isomers especially in CLA-fortified milk powder but also in fermented milk, yogurt, and milk-juice blend.
\end{abstract}

Key words: conjugated linoleic acid, milk product, fatty acid composition

\section{INTRODUCTION}

The generic name "conjugated linoleic acid" (CLA) is a collective term embracing all octadecadienoic acids

Received October 20, 2006.

Accepted January 31, 2007.

${ }^{1}$ Corresponding author: jfontecha@if.csic.es
(C18:2) with a conjugated double bond system in the $7-9,8-10,9-11,10-12,11-13$, and $12-14$ positions and a cis, cis, cis, trans, trans, cis, and trans, trans geometrical configuration. Recently, evidence has suggested that individual CLA isomers might act differently in biological systems and contribute in different ways in their beneficial or potential side effects (Belury, 2002a; Khanal, 2004; Pariza, 2004; Parodi, 2004; Terpstra, 2004). Data from animal models have been used to suggest that the CLA isomer C18:2 cis-9, trans-11, also known as rumenic acid (RA), is responsible for the anticarcinogenic properties of CLA, as well as growthpromoting and antiatherogenic effects (Ip et al., 1994, 1996, 2002; Belury, 2002b; Masso-Welch, et al., 2002, 2004), whereas the C18:2 cis-10, trans- 12 isomer is responsible for the observed weight loss and muscle-mass enhancement effects (Gaullier et al., 2004; MalpuechBrugere et al., 2004).

The advantageous nutritional properties and benefits associated with CLA have important implications for food industries whose challenge is the production of functional foods with high health-promoting capacities.

Most full-fat dairy products contain CLA in quantities varying from 6 to $16 \mathrm{mg} / \mathrm{g}$ of total fat content, with lesser amounts in meat (Parodi, 1977), 85 to 95\% of which is present as the C18:2 cis-9, trans-11 isomer. Therefore, estimates of CLA daily intake from food sources range from 150 to $212 \mathrm{mg} / \mathrm{d}$ (McGuire et al., 1997) or from $300 \mathrm{mg}$ to $1.5 \mathrm{~g}$ (Fritsche et al., 1999) although actual intake appears to be dependent on gender and intake of food from animal or vegetable origins. Ip et al. (1994) estimated that a 70-kg human should consume $3.0 \mathrm{~g}$ of CLA/d to achieve maximum health benefits. Similarly, CLA supplementation in overweight subjects after weight loss seems to aid the regain of fat-free mass at experimental doses of 1.8 and $3.6 \mathrm{~g} /$ $\mathrm{d}$ (Kamphuis et al., 2003). Nevertheless, the extrapolation of CLA effects observed in animals to the human situation should be made with caution.

There are different approaches to increasing the human dietary intake of CLA isomers from food. One is to modify the feeding diets of ruminants with supplements 
rich in polyunsaturated fatty acids (PUFA) that provide lipid substrates for the production of cis-9, trans-11 C18:2 or trans-11 C18:1 (trans-vaccenic acid; Stanton et al., 2003; Khanal and Olson, 2004; Luna et al., 2005b). This strategy has proved to be effective but the concentration of CLA in the milk that is richest in CLA is low compared with other commercial sources of CLA, such as CLA capsules or CLA-fortified dairy products, that provide an additional oral source of CLA to supplement the human diet and complement the CLA amount contained in foods.

The interest in CLA as a nutritional supplement is high and different products are now offered commercially (Sæbø, 2003). Various methods are available to produce synthetic CLA but alkaline isomerization of linoleic acid is the most common (Villeneuve et al., 2005). These commercial supplements contain 50 to 80\% CLA and correspond to a complex mixture of isomers, with the C18:2 cis-9, trans-11 and C18:2 cis-10, trans-12 isomers being the most abundant, accounting for approximately $90 \%$ at a 1:1 level, with the remaining isomers consisting of all cis- and all trans-isomers of 9,11-, 10,12-, and 11,13-C18:2 (Ma et al., 1999).

Studies of CLA-fortified products, including their behavior during production and storage, would support the development of consumer-acceptable strategies and processing systems to produce CLA-enriched products and enhanced dairy foods of proven quality.

Although Campbell et al. (2003) prepared and compared 3 samples of fluid milk containing $2 \%$ total fat (2\% milk fat; $1 \%$ CLA oil:1\% milk fat; and 2\% CLA oil) on the sensory, chemical, and physical characteristics, the total fatty acid compositions, including CLA and CLA isomer distribution, have not been examined in commercially available CLA-fortified dairy products.

In the present study, a CLA oil supplement and commercial CLA-fortified dairy products were analyzed for CLA isomers and total fatty acid composition using a gas chromatographic method combined with a silver ion $\left(\mathrm{Ag}^{+}\right)$-HPLC method. To our knowledge, this study demonstrated for the first time significant differences among commercially available CLA-fortified dairy products and their evaluation during processing and storage.

The results of the effect of processing conditions, storage, and aging on the CLA content of various types of dairy products are unclear. With regard to cheeses, reports and reviews present results for individual varieties, often in the belief that CLA levels may vary due to different processing conditions. Herzallah et al. (2005) reported CLA decreases of 21 and $53 \%$ in cheeses heated in a microwave oven for 5 and $10 \mathrm{~min}$, respectively. Nevertheless, these effects are likely to be small, and variations in CLA levels are similar to the levels in the starting milk (Shantha et al., 1995; Dhiman et al., 1999; Gnädig and Sébédio, 2002; Luna et al., 2005c). However, other studies detected new CLA isomers in ripened cheeses (Werner et al., 1992; Lavillonière et al., 1998; Sehat et al., 1998) and it was hypothesized that biohydrogenation of linolenic acid in cheese could lead to the formation of CLA isomers as intermediates.

In this article, industrial-scale production of milk products enriched with a commercial CLA oil supplement was conducted. Fatty acid composition and CLA isomer profiles were determined to investigate their development during processing and $10 \mathrm{wk}$ of storage. Our aim was to determine whether there were any compositional differences in these products containing high concentrations of healthy fatty acids.

\section{MATERIALS AND METHODS}

\section{Samples and Standards}

Five commercially available CLA-fortified dairy products in Spain (milk, fermented milk, yogurt, fresh cheese, milk-juice blend) and a CLA-fortified milk powder (noncommercial) were shipped from the manufacturer (Capsa Inc., Oviedo, Spain) to the laboratory in isothermal containers at $4^{\circ} \mathrm{C}$. Samples were maintained at this temperature until fat extraction was carried out. Each product consisted of a different concentration of a CLA oil added as a supplement such that the consumer received $2.4 \mathrm{~g} / \mathrm{d}$ of CLA when consuming the recommended 2 servings (Table 1). Skim milk with CLA oil added was dual-homogenized $(20,000 \pm 1,000 \mathrm{kPa})$ and treated by an indirect UHT process at $142^{\circ} \mathrm{C}$ for $6 \mathrm{~s}$. Milk powder was obtained after atomization of the CLAenriched milk sample. Fermented milk and yogurt with CLA oil added were dual-homogenized and HTST-pasteurized at $95^{\circ} \mathrm{C}$, and traditional yogurt cultures (Lactobacillus bulgaricus and Streptococcus thermophilus) were added. Fresh cheese was made from skim milk with CLA oil, salt, and rennet; no starter was added. Milk-juice blend (20\% fruit from concentrate) was made from skim milk with CLA oil added, pasteurized at $100^{\circ} \mathrm{C}$ for $30 \mathrm{~s}$, and single-homogenized. A sample of the CLA oil (Tonalin-80, Cognis, Düsseldorf, Germany) used to fortify the milk products was also donated by the manufacturer and analyzed. A total of 9 samples from each product ( 3 samples at 3 times: 1,5 and 10 wk of storage at $4^{\circ} \mathrm{C}$ ) were analyzed except for the CLA oil supplement and milk powder, for which storage studies were not carried out.

Pure and mixed CLA isomer methyl esters (C18:2 cis-9, trans-11 CLA and C18:2 cis-10, trans-12 CLA) were purchased from Nu-Chek Prep (Elysian, MN). For quantitative determinations of total fatty acid methyl esters (FAME), an anhydrous milk fat (reference mate- 
Table 1. Product information of the different fortified dairy products studied

\begin{tabular}{|c|c|c|c|c|c|c|}
\hline \multirow[b]{2}{*}{ Component } & \multicolumn{6}{|c|}{ Product } \\
\hline & Milk & $\begin{array}{c}\text { Milk } \\
\text { powder }\end{array}$ & $\begin{array}{l}\text { Fermented } \\
\text { milk }\end{array}$ & Yogurt & Cheese & $\begin{array}{c}\text { Milk-juice } \\
\text { blend }\end{array}$ \\
\hline $\mathrm{pH}$ & 6.7 & 6.7 & 4.0 & 4.6 & 6.5 & 3.7 \\
\hline Fat, \% & 1.0 & 10 & 2 & 1.6 & 1.5 & 0.8 \\
\hline Protein, \% & 3.2 & 32 & 2.6 & 5.0 & 13.4 & 0.3 \\
\hline Tonalin, $1 \%$ & 0.6 & 6 & 1.5 & 1.2 & 1.2 & 0.6 \\
\hline Starter culture & No & No & Yes & Yes & No & No \\
\hline Serving size, $\mathrm{g}$ & 250 & 25 & 100 & 120 & 125 & 250 \\
\hline CLA $^{2}$ per serving, $\mathrm{g}$ & 1.2 & 1.2 & 1.2 & 1.2 & 1.2 & 1.2 \\
\hline
\end{tabular}

rial BCR-164; EU Commission; Brussels, Belgium, purchased from Fedelco Inc., Madrid, Spain) was used. An internal standard $(12.4 \mathrm{mg} / \mathrm{mL}$ of $\mathrm{C} 13: 0$ as triacylglyceride; Sigma, St. Louis, MO) was also used.

\section{Lipid Extraction and Fatty Acid Derivatization}

Milk fat extraction was carried out according to standard methods (ISO-IDF, 2001). The fat residue extracted was stored frozen at $-20^{\circ} \mathrm{C}$ until analysis. Fatty acid methyl esters were prepared by base-catalyzed methanolysis of the glycerides ( $2 \mathrm{~N} \mathrm{KOH}$ in methanol) according to standard methods (ISO-IDF, 2002).

\section{Gas Chromatography-Flame-Ionization Detection Analyses}

Fatty acid methyl esters were analyzed on a PerkinElmer chromatograph (model Autosystem, Beaconsfield, UK) with a flame-ionization detector (FID). Fatty acid methyl esters were separated using a fusedsilica capillary column $(100 \mathrm{~m} \times 0.25 \mathrm{~mm}$ i.d. $\times 0.2 \mu \mathrm{m}$ film thickness, CP-Sil 88, Chrompack, Middelburg, the Netherlands). The column was held at $100^{\circ} \mathrm{C}$ for $1 \mathrm{~min}$ after injection, then the temperature was increased at $7^{\circ} \mathrm{C} / \mathrm{min}$ to $170^{\circ} \mathrm{C}$, held for $55 \mathrm{~min}$, then increased at $10^{\circ} \mathrm{C} / \mathrm{min}$ to $230^{\circ} \mathrm{C}$, and held there for $33 \mathrm{~min}$. Helium was the carrier gas with a column inlet pressure set at $214 \mathrm{kPa}$ (30 Psig) and a split ratio of 1:20. The injection volume was $0.5 \mu \mathrm{L}$. The CLA isomers were determined and identified by GC-FID by comparing the supplement CLA oil and CLA standards, in accordance with our laboratory's previous studies (Luna et al., 2005a).

\section{Silver Ion-HPLC}

Silver ion $\left(\mathrm{Ag}^{+}\right)$-HPLC separation of CLA methyl esters was carried out using an HPLC (Shimadzu Vp Series, Duisburg, Germany) equipped with a UV detector operated at $233 \mathrm{~nm}$. Fatty acid methyl esters were separated using an analytical column $(4.6 \mathrm{~mm}$ i.d. $\times$ $250 \mathrm{~mm}$ stainless steel; $5 \mu \mathrm{m}$ particle size; ChromSpher 5 Lipid column, Varian-Chrompack Int., Middelburg, the Netherlands). The mobile phase was $0.1 \%$ acetonitrile in hexane, operated isocratically at a flow rate of $1.0 \mathrm{~mL} / \mathrm{min}$. The flow was initiated $0.5 \mathrm{~h}$ before the sample injection and the injection volume was $10 \mu \mathrm{L}$. Pure and mixed CLA FAME isomers from Nu-Chek Prep were used as standards.

\section{Statistical Analysis}

Data were analyzed using the ANOVA procedure of the SPSS package (SPSS 11.0 for Windows, SPSS Inc., Chicago, IL). Multiple range tests were applied to determine significance between different treatments.

\section{RESULTS AND DISCUSSION}

\section{FAME Composition of CLA-Enriched Dairy Products by GC-FID}

Table 2 shows FAME percentages in the CLA oil sample (Tonalin) and in 6 CLA-enriched products after 1,5 , and $10 \mathrm{wk}$ of refrigerated storage. As expected, commercial CLA oil supplements typically comprised 2 major isomers: C18:2 cis-9, trans-11 CLA and C18:2 cis10, trans-12 CLA. Minor CLA isomers detected by GCFID (Figure 1) included cis-11, trans-13; cis-9, cis-11; and cis-10, cis-12. The trans-8, cis-10 isomer is included in the cis-9, trans-11 peak. Other minor CLA isomers in the chromatographic area studied included an overlapping of at least 3 trans/trans isomers that eluted as a single peak (trans-8, trans-10; trans-9, trans-11; and trans-10, trans-12).

The main differences in the FAME profiles between the analyzed products were related to their CLA content. The CLA oil supplement contained around 80\% of total CLA whereas the supplemented samples contained in the range of 50 to $75 \%$ of total CLA, due to 


\begin{tabular}{|c|c|c|c|c|c|c|c|c|c|c|}
\hline \multirow{2}{*}{$\begin{array}{l}\text { Sample }{ }^{1} \\
\text { (wk of storage) }\end{array}$} & \multicolumn{10}{|c|}{ Fatty acids, ${ }^{2} \%$ of total fatty acids } \\
\hline & $\mathrm{C} 16: 0$ & C18:0 & C18:1 c9 & $\mathrm{C} 18: 2 \mathrm{c} 9, \mathrm{c} 12$ & $\mathrm{C} 18: 2 \mathrm{c} 9, \mathrm{t} 11$ & $\mathrm{C} 18: 2 \mathrm{t} 10, \mathrm{c} 12$ & SFA & MUFA & PUFA & CLA \\
\hline CLA oil supplement & $0.20 \pm 0.02$ & $2.54 \pm 0.12$ & $13.37 \pm 0.57$ & $0.43 \pm 0.06$ & $39.65 \pm 0.76$ & $38.12 \pm 0.76$ & $2.82 \pm 0.13$ & $14.12 \pm 0.79$ & $82.37 \pm 1.07$ & $81.27 \pm 1.04$ \\
\hline Milk powder & $7.37 \pm 0.26$ & $4.14 \pm 0.15$ & $13.21 \pm 0.45$ & $0.47 \pm 0.07$ & $31.11 \pm 0.79$ & $32.03 \pm 0.69$ & $18.17 \pm 0.54$ & $15.33 \pm 0.69$ & $66.12 \pm 0.94$ & $64.71 \pm 0.84$ \\
\hline 1 & $11.68 \pm 0.61$ & $5.46 \pm 0.21$ & $17.52 \pm 0.67$ & $1.31 \pm 0.17$ & $24.61 \pm 1.83$ & $23.55 \pm 1.14$ & $26.61 \pm 1.85$ & $20.37 \pm 1.31$ & $52.41 \pm 3.32$ & $49.91 \pm 0.77$ \\
\hline 5 & $12.14 \pm 0.76$ & $5.24 \pm 0.35$ & $15.80 \pm 0.94$ & $1.32 \pm 0.25$ & $24.45 \pm 0.73$ & $24.05 \pm 0.67$ & $26.51 \pm 1.15$ & $18.58 \pm 1.47$ & $53.70 \pm 1.53$ & $50.70 \pm 0.52$ \\
\hline 10 & $11.87 \pm 0.93$ & $5.15 \pm 0.14$ & $16.80 \pm 0.49$ & $1.39 \pm 0.18$ & $24.01 \pm 0.56$ & $23.50 \pm 0.47$ & $26.09 \pm 0.73$ & $19.88 \pm 1.37$ & $52.71 \pm 1.41$ & $49.69 \pm 0.85$ \\
\hline \multicolumn{11}{|l|}{ Fermented milk } \\
\hline 1 & $1.62 \pm 0.17$ & $2.54 \pm 0.20$ & $14.55 \pm 0.48$ & $0.35 \pm 0.02$ & $38.03 \pm 0.74$ & $37.75 \pm 0.39$ & $4.98 \pm 0.17$ & $15.51 \pm 0.59$ & $79.01 \pm 0.66$ & $77.34 \pm 0.99$ \\
\hline 5 & $1.63 \pm 0.12$ & $2.33 \pm 0.22$ & $14.62 \pm 0.31$ & $0.36 \pm 0.04$ & $37.90 \pm 0.67$ & $37.42 \pm 0.57$ & $4.76 \pm 0.14$ & $15.65 \pm 0.44$ & $78.94 \pm 0.58$ & $77.19 \pm 0.89$ \\
\hline 10 & $1.75 \pm 0.19$ & $2.44 \pm 0.18$ & $14.74 \pm 0.53$ & $0.37 \pm 0.03$ & $37.21 \pm 0.86$ & $37.00 \pm 0.35$ & $5.08 \pm 0.21$ & $15.86 \pm 0.58$ & $78.19 \pm 0.82$ & $76.52 \pm 0.76$ \\
\hline \multicolumn{11}{|l|}{ Yogurt } \\
\hline 1 & $5.96 \pm 0.83$ & $3.79 \pm 0.34$ & $16.18 \pm 0.52$ & $0.76 \pm 0.15$ & $32.10 \pm 1.00$ & $31.11 \pm 1.61$ & $14.24 \pm 0.93$ & $17.80 \pm 0.51$ & $67.34 \pm 2.07$ & $65.22 \pm 2.07$ \\
\hline 5 & $5.27 \pm 0.56$ & $3.45 \pm 0.50$ & $15.68 \pm 1.69$ & $0.68 \pm 0.13$ & $32.68 \pm 2.10$ & $32.28 \pm 0.71$ & $13.60 \pm 0.68$ & $17.46 \pm 1.73$ & $68.60 \pm 1.17$ & $66.58 \pm 1.30$ \\
\hline 10 & $6.08 \pm 0.50$ & $3.77 \pm 0.66$ & $15.36 \pm 1.86$ & $0.77 \pm 0.21$ & $32.12 \pm 3.20$ & $31.28 \pm 0.81$ & $14.66 \pm 0.44$ & $17.17 \pm 1.15$ & $67.42 \pm 1.27$ & $65.28 \pm 1.54$ \\
\hline \multicolumn{11}{|c|}{ 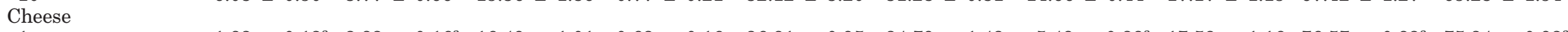 } \\
\hline 1 & $1.82 \pm 0.12^{\mathrm{a}}$ & $2.82 \pm 0.16^{\mathrm{a}}$ & $16.49 \pm 1.01$ & $0.63 \pm 0.16$ & $36.81 \pm 0.95$ & $34.79 \pm 1.43$ & $5.48 \pm 0.38^{\mathrm{a}}$ & $17.58 \pm 1.16$ & $76.57 \pm 0.82^{\mathrm{a}}$ & $75.34 \pm 0.92^{\mathrm{a}}$ \\
\hline 5 & $3.78 \pm 0.19^{b}$ & $3.78 \pm 0.29^{b}$ & $15.06 \pm 1.31$ & $0.62 \pm 0.12$ & $36.73 \pm 1.30$ & $34.14 \pm 1.22$ & $7.48 \pm 0.47^{\mathrm{b}}$ & $16.29 \pm 1.19$ & $74.82 \pm 0.89^{\mathrm{a}}$ & $74.41 \pm 1.53^{\mathrm{a}}$ \\
\hline 10 & $3.30 \pm 0.12^{\mathrm{b}}$ & $3.42 \pm 0.13^{b}$ & $16.47 \pm 0.73$ & $0.82 \pm 0.21$ & $34.59 \pm 1.47$ & $32.86 \pm 1.15$ & $8.42 \pm 0.54^{\mathrm{b}}$ & $18.01 \pm 1.14$ & $72.32 \pm 1.33^{\mathrm{b}}$ & $70.85 \pm 1.26^{\mathrm{b}}$ \\
\hline \multicolumn{11}{|l|}{ Milk-juice blend } \\
\hline 1 & $2.37 \pm 0.22$ & $5.02 \pm 0.45$ & $13.71 \pm 0.81$ & $0.37 \pm 0.11$ & $37.50 \pm 0.94$ & $36.83 \pm 0.96$ & $8.08 \pm 0.54$ & $14.46 \pm 1.44$ & $77.46 \pm 1.21$ & $76.22 \pm 1.24$ \\
\hline 5 & $2.69 \pm 0.52$ & $3.98 \pm 0.50$ & $12.25 \pm 1.04$ & $0.30 \pm 0.15$ & $39.14 \pm 1.08$ & $37.69 \pm 1.15$ & $7.85 \pm 0.26$ & $12.94 \pm 1.10$ & $78.83 \pm 1.10$ & $78.03 \pm 1.37$ \\
\hline 10 & $2.42 \pm 0.15$ & $4.89 \pm 0.53$ & $14.03 \pm 0.84$ & $0.40 \pm 0.07$ & $36.72 \pm 1.29$ & $36.71 \pm 0.51$ & $8.36 \pm 0.36$ & $14.92 \pm 0.63$ & $76.69 \pm 1.32$ & $75.61 \pm 1.31$ \\
\hline
\end{tabular}

${ }^{\mathrm{a}, \mathrm{b}}$ Means within a product and column with different superscripts $\operatorname{differ}(P<0.05)$.

${ }^{1}$ The CLA oil supplement and milk powder were not evaluated over the storage period.

${ }^{2} \mathrm{c}=$ cis $; \mathrm{t}=$ trans $; \mathrm{SFA}=$ saturated fatty acids; MUFA = monounsaturated fatty acids; PUFA = polyunsaturated fatty acids. 


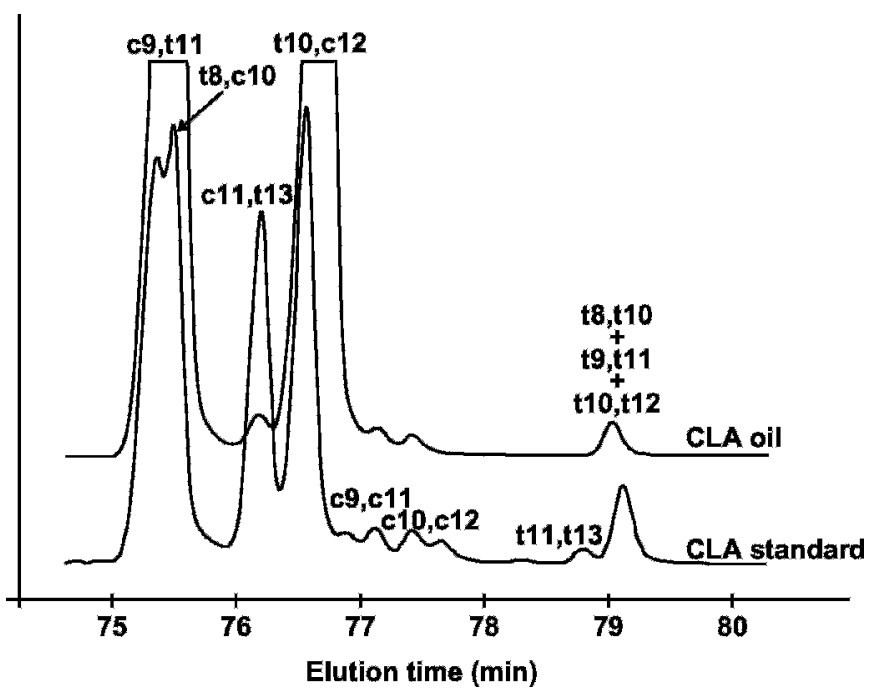

Figure 1. Fatty acid methyl ester profile by gas chromatography with flame-ionization detection of conjugated linoleic acid (CLA) oil used as a supplement to fortify the studied dairy products and profile of the standard CLA methyl ester mixture (Nu-Chek Prep Inc., Elysian, $\mathrm{MN}) . \mathrm{c}=$ cis, $\mathrm{t}=$ trans.

the presence of individual non-CLA fatty acids. Thus, the lower occurrence of CLA in some of the samples, such as milk and yogurt (50 and $65 \%$, respectively) was correlated with the higher presence of milk fat fatty acids. The percentage of saturated fatty acids (SFA) in milk and yogurt (26 and 14\%, respectively), and of short- and medium-chain fatty acids (2.5 and $6.9 \%$ in milk; 1.2 and $3.2 \%$ in yogurt, respectively) was high, which is related to the presence of milk fat in the products. The occurrence of milk fat fatty acids in some of the studied products (especially in milk) was higher than would be expected in a skim milk.

The high ratio of SFA to PUFA in dairy fats is undesirable from a nutritional perspective due to the link between saturated fats and increased levels of serum cholesterol and heart disease. Nevertheless, in all of the products studied, C18:2 cis-9, trans-11 and C18:2 cis-10, trans-12 CLA were the predominant fatty acids present. All samples had a similar ratio of C18:2 cis-9, trans-11 to trans-10, cis-12 CLA, which ranged from 0.97 to 1.05 . Moreover, in these studied samples, the ratio of CLA to PUFA was greater than 0.95 in all cases. In addition to CLA, oleic acid (C18:1 cis-9) was the most abundant fatty acid (around 15\%) and linoleic acid (C18:2 cis-9, cis-12) was also present, giving all of the studied dairy products a balanced SFA to PUFA ratio.

As mentioned earlier, other minor CLA isomers did not occur as pure chromatographic peaks but were overlapped as indicated by a single peak (trans-8, trans10; trans-9, trans-11; and trans-10, trans-12; Figure 1).
These compounds were detected in all products at levels ranging from 1.6 to $3.5 \%$.

\section{Effects of Processing and Refrigerated Storage of Fatty Acid Composition by GC}

Due to the existence of variable amounts of milk fat present in the CLA-fortified samples, comparisons of the fatty acid content between CLA oil and CLA-enriched samples immediately after preparation and treatment could not be determined by GC analysis. Instead, it was studied by $\mathrm{Ag}^{+}$-HPLC of the total CLA fraction and individual isomers as discussed below.

Results obtained throughout the refrigerated storage of CLA-fortified dairy products for 1,5 , and $10 \mathrm{wk}$ showed that significant differences were found only in the fresh cheese sample. Both C18:2 cis-9, trans-11 CLA and C18:2 cis-10, trans-12 CLA isomers decreased but not significantly after 5 wk of storage; subsequently, a significant loss of the total CLA and total PUFA fraction occurred within the same period of storage (Table 2). Campbell et al. (2003) found a significant loss of C18:2 cis-9, trans-11 CLA after HTST pasteurization of $2 \%$ CLA-fortified skim milk. The same authors reported a significant decrease of C18:2 cis-9, trans-11 after $3 \mathrm{wk}$ of refrigerated storage compared with the levels of this isomer at 1 and $2 \mathrm{wk}$ of storage. These reductions of C18:2 cis-9, trans-11 were attributed to the heat processing and to excessive microbial growth during the storage of the milk samples.

In the fermented milk studied in this work (a CLAenriched sample with yogurt culture), declines of C18:2 cis-9, trans- 11 and C18:2 trans-10, cis-12 CLA were also detected after wk 5 of storage, but were not statistically significant. Nevertheless, no similar decreases were found in yogurt. No change was observed in milk or milk-juice blend samples during storage. Xu et al. (2005) demonstrated that the combination of most probiotic bacteria with the yogurt cultures produced slightly higher contents of C18:2 cis-9, trans-11 and C18:2 trans-10, cis-12 CLA, but it did not occur in yogurt culture alone (i.e., without probiotic bacteria) after 14 d of storage.

\section{CLA Isomer Composition of CLA-Enriched Products by $\mathrm{Ag}^{+}-\mathrm{HPLC}$}

The use of $\mathrm{Ag}^{+}$-HPLC is currently the most effective way of separating and quantifying CLA isomers. Conjugated linoleic acid FAME are selectively detected by their characteristic UV absorbance at $233 \mathrm{~nm}$; nonconjugated FAME respond poorly at this wavelength. There are about 20 different CLA isomers in natural milk fat based on $\mathrm{Ag}^{+}$-HPLC separation (Sehat et al., 1998). 
Table 3. Conjugated linoleic acid (CLA) isomer composition of CLA oil supplement and CLA-enriched products after 1, 5, and 10 wk of storage

\begin{tabular}{|c|c|c|c|c|c|c|c|c|}
\hline \multirow{2}{*}{$\begin{array}{l}\text { Sample } \\
\text { (wk of storage) }\end{array}$} & \multicolumn{8}{|c|}{ CLA isomer composition, ${ }^{1} \%$ of total CLA } \\
\hline & $\mathrm{t} 11, \mathrm{t} 13$ & $\mathrm{t} 10, \mathrm{t} 12$ & $\mathrm{c} 11, \mathrm{t} 13$ & $\mathrm{t} 10, \mathrm{c} 12$ & c9, t11 & $\mathrm{t} 8, \mathrm{c} 10$ & c9, c11 & $\mathrm{c} 10, \mathrm{c} 12$ \\
\hline CLA oil supplement & $0.56 \pm 0.06^{\mathrm{x}}$ & $0.49 \pm 0.05^{\mathrm{x}}$ & $1.65 \pm 0.23^{\mathrm{x}}$ & $45.74 \pm 1.84$ & $48.57 \pm 0.61$ & $1.76 \pm 0.32^{\mathrm{x}}$ & $0.54 \pm 0.16$ & $0.55 \pm 0.08$ \\
\hline 1 & $0.65 \pm 0.12$ & $0.63 \pm 0.12$ & $1.49 \pm 0.28$ & $44.96 \pm 1.85$ & $49.46 \pm 1.88$ & $1.65 \pm 0.28$ & $0.51 \pm 0.15$ & $0.52 \pm 0.10$ \\
\hline 5 & $1.10 \pm 0.45$ & $1.04 \pm 0.49$ & $1.64 \pm 0.15$ & $46.12 \pm 1.57$ & $47.28 \pm 1.31$ & $1.49 \pm 0.52$ & $0.43 \pm 0.09$ & $0.58 \pm 0.05$ \\
\hline 10 & $1.08 \pm 0.45$ & $1.03 \pm 0.46$ & $1.37 \pm 0.11$ & $47.58 \pm 1.70$ & $45.91 \pm 1.67$ & $1.82 \pm 0.13$ & $0.23 \pm 0.08$ & $0.53 \pm 0.04$ \\
\hline 5 & $0.43 \pm 0.06$ & $0.37 \pm 0.04$ & $0.29 \pm 0.10$ & $47.82 \pm 1.42$ & $49.82 \pm 1.82$ & $0.24 \pm 0.04$ & $0.50 \pm 0.05$ & $0.51 \pm 0.04$ \\
\hline 10 & $0.45 \pm 0.04$ & $0.41 \pm 0.03$ & $0.34 \pm 0.20$ & $47.78 \pm 1.02$ & $49.11 \pm 1.75$ & $0.27 \pm 0.05$ & $0.45 \pm 0.08$ & $0.45 \pm 0.07$ \\
\hline \multicolumn{9}{|l|}{ Yogurt } \\
\hline 1 & $0.58 \pm 0.20$ & $0.54 \pm 0.11$ & ND & $46.18 \pm 1.07$ & $49.30 \pm 0.64$ & $1.11 \pm 0.15$ & $0.48 \pm 0.25$ & $0.61 \pm 0.13$ \\
\hline 5 & $0.44 \pm 0.17$ & $0.39 \pm 0.17$ & ND & $48.51 \pm 1.47$ & $48.72 \pm 0.46$ & $1.23 \pm 0.11$ & $0.47 \pm 0.18$ & $0.51 \pm 0.07$ \\
\hline 10 & $0.55 \pm 0.14$ & $0.48 \pm 0.13$ & ND & $46.77 \pm 1.87$ & $49.31 \pm 0.69$ & $1.05 \pm 0.15$ & $0.39 \pm 0.10$ & $0.49 \pm 0.14$ \\
\hline \multicolumn{9}{|l|}{ Cheese } \\
\hline 1 & $0.52 \pm 0.04$ & $0.47 \pm 0.04$ & ND & $47.40 \pm 1.27$ & $49.80 \pm 2.04$ & $0.55 \pm 0.15^{\mathrm{y}}$ & $0.61 \pm 0.18$ & $0.58 \pm 0.14$ \\
\hline 5 & $0.49 \pm 0.05$ & $0.44 \pm 0.04$ & ND & $46.67 \pm 1.52$ & $52.20 \pm 1.16$ & $0.37 \pm 0.06$ & ND & ND \\
\hline 10 & $0.50 \pm 0.06$ & $0.46 \pm 0.04$ & ND & $46.93 \pm 1.03$ & $52.08 \pm 1.92$ & ND & ND & ND \\
\hline
\end{tabular}

${ }^{\mathrm{x}, \mathrm{y}}$ Means within CLA oil supplement and a wk 1 storage product with different superscripts $\operatorname{differ}(P<0.05)$; differences by industrial treatment.

${ }^{\mathrm{a}, \mathrm{b}}$ Means within a product and column with different superscripts differ $(P<0.05)$; differences by refrigeration storage.

${ }^{1} \mathrm{c}=$ cis $; \mathrm{t}=$ trans $; \mathrm{ND}=$ not determined.

The CLA isomer compositions (\% of total CLA) of the 6 CLA-enriched products studied after 1,5 , and $10 \mathrm{wk}$ of storage are shown in Table 3 . To determine the possible variations in CLA isomer composition during the processing of the CLA-enriched products, CLA-supplemented oil was used as a control during the first week of storage of the different products. Silver ion-HPLC identification of more than 10 different peaks attributed to CLA isomers was based on coinjection with reference material because of retention time irreproducibility and in accordance with the elution order, as we reported in previous studies with the same chromatographic conditions (Luna et al., 2005a). The $\mathrm{Ag}^{+}$-HPLC profile of lipid sample was shown to separate the different C18:2 trans, trans compounds followed by a chromatographic zone where cis, trans and trans, cis isomers were located and finally the cis, cis CLA isomers eluted. The most prominent peaks in all products corresponded, as expected, to C18:2 cis-9, trans-11 and trans-10, cis-12 CLA isomers, which accounted for about $95 \%$ of total CLA. All enriched milk products showed a similar ratio of C18:2 cis-9, trans-11 to trans-10, cis-12 CLA, which ranged from 0.95 to 0.98 .

The CLA isomer percentages of the enriched products studied differed substantially from proportions reported for total CLA fatty acids in cow's milk fat, in which most of the CLA corresponds to RA (about 80\%) and which would be a poor source of the C18:2 trans10, cis-12 CLA isomer (Sehat et al., 1998). Similarly, the C18:2 trans-7, cis-9 CLA isomer is the second greatest in cow's milk fat (5 to 10\% of total CLA), whereas its presence in the products of the current study seemed to be negligible.

Noticeable percentages of the isomers C18:2 cis-11, trans-13 and trans-8, cis-10 were found in the fortified products (1.8 and $1.7 \%$, respectively, in the CLA-supplemented oil and up to $2.4 \%$ in CLA-enriched cheese). Amounts of $4.2 \%$ of C18:2 cis-11, trans-13 and lower than $1 \%$ of $\mathrm{C} 18: 2$ trans- 8 , cis-10 of total CLA were reported by Luna et al. (2005a) in ewe's milk.

Another 4 peaks eluting in the C18:2 trans, trans CLA region were assigned to trans-9, trans-11; trans10, trans-12; trans-11, trans-13; and trans-12, trans-14. Two of these isomers (trans-9, trans-11 and trans-12, trans-14) were in trace amounts in the CLA oil supplement and not detectable in the analyzed samples, whereas the 2 peaks identified as trans-10, trans- 12 and trans-11, trans-13 accounted for 0.5 and $0.6 \%$ of the CLA-oil supplement, respectively.

In the C18:2 cis, cis CLA chromatographic area, 2 isomers with comparable amounts $(0.6 \%)$ were detected in the CLA oil and assigned to cis-9, cis-11 and cis-10, cis-12. These isomers were not detected in different dairy foods when CLA profiles were researched using 
$\mathrm{Ag}^{+}$-HPLC in similar conditions (Sehat et al., 1999; Luna et al., 2005a).

\section{Effects of Processing and Storage on CLA Isomers by $\mathrm{Ag}^{+}-\mathrm{HPLC}$}

The important quality issues for CLA-supplemented products are total CLA content and isomeric distribution that could be altered by the effect of processing conditions, storage, and aging.

To determine significant variations in CLA isomer composition during processing of the CLA-enriched products, CLA-supplemented oil was used as a control in the first week of storage of the different products. The CLA isomer contents as a percentage of total CLA are shown in Table 3. No significant changes were found in the content of the major isomers $(\mathrm{C} 18: 2 \mathrm{cis}-9$, trans11 and C18:2 trans-10, cis-12 CLA) as a consequence of treatment or refrigerated storage up to $10 \mathrm{wk}$ in any of the CLA-enriched dairy products studied. Nevertheless, this study showed that the industrial process of the product or thermal treatment resulted in a significant decrease of some of the minor CLA isomers such as cis11, trans-13 and trans-8, cis-10 in milk powder, fermented milk, yogurt, and milk-juice blend.

In the CLA-enriched fresh cheese studied, the formation of new isomers was not found, but a significant decrease of the minor isomer C18:2 cis-11, trans-13 during refrigerated storage, and even the disappearance of some other C18:2 cis, cis isomers as cis-9, cis-11 and cis-10, cis-12, was observed. Decreases in these minor isomers resulted in undetectable levels in other samples, such as the milk-juice blend.

Isomer contents in the C18:2 trans, trans region (mainly trans-9, trans-11 and trans-10, trans-12 isomers) were found to be low in all CLA-enriched products except for milk powder, in which levels increased significantly after the thermal process. The level of C18:2 trans, trans isomers was also positively influenced in milk after $5 \mathrm{wk}$ of storage but not significantly. The increase in the content of C18:2 trans, trans isomers has been related to lipid transformation by heat treatment (Precht et al., 1999; Juanéda et al., 2003; Herzallah et al., 2005). It has been reported that the trans double bond is more stable compared with the cis bond in the same environmental conditions, and that the level of trans/trans-CLA may be elevated by reaction conditions that favor thermodynamic products such as a higher reaction temperature and longer reaction time (Bruice and Lightstone, 1999). Destaillats et al. (2005) found that severe thermal processes result in sigmatropic isomerization of $\mathrm{RA}$ resulting in the formation of $\mathrm{C} 18: 2$ trans-8, cis-10, which can be used as a marker of heat treatment of natural fats and oils containing CLA. Sig- matropic rearrangement has been also described between the isomers C18:2 trans-10, cis-12 and cis-11, trans-13, and between C18:2 cis-9, trans-11 and trans8, cis-10, with a significant increase of C18:2 trans, trans isomers from cis, trans; trans, cis; and cis, cis isomers.

In summary, this study indicates that the total CLA content of different commercially available CLA-enriched dairy products (supplemented using Tonalin-80, an oil supplement with $80 \%$ CLA) varied considerably from 50 to $75 \%$ depending on the presence of milk fat in the products. The CLA isomers C18:2 cis-9, trans- 11 and C18:2 trans-10, cis-12 were the predominant fatty acids present in all products, at a ratio ranging from 0.97 to 1.05 . These major isomers were not affected by the processing used and did not significantly decrease after $10 \mathrm{wk}$ of storage. Only a significant loss of total CLA throughout the refrigerated storage of fresh cheese sample was found, possibly related to an increase in microbiota growth. Nevertheless, refrigerated storage and, particularly, thermal treatment resulted in significant decreases or disappearance of some of the minor CLA isomers and a significant increase of C18:2 trans, trans isomers from cis, trans; trans, cis; and cis, cis isomers especially in CLA-fortified milk powder but also in fermented milk, yogurt, and milk-juice blend.

\section{ACKNOWLEDGMENTS}

The authors are grateful to the Ministerio de Ciencia y Tecnologia (project AGL2003-01712) and the Comunidad Autonoma de Madrid (project S-0505/AGR-0153) for financial support for this research. They would also like to thank Corporación Alimentaria Peñasanta S.A. (CAPSA) for their support in development of this project and for generously supplying of samples; and the kindly help of D. José Ramón Iglesias.

\section{REFERENCES}

Belury, M. A. 2002a. Dietary conjugated linoleic acid in health: Physiological effects and mechanisms of action. Annu. Rev. Nutr. 22:505-531.

Belury, M. A. 2002b. Inhibition of carcinogenesis by conjugated linoleic acid: Potential mechanisms of action. J. Nutr. 132:2995-2998.

Bruice, T. C., and F. C. Lightstone. 1999. Ground state and transition state contributions to the rates of intramolecular and enzymatic reactions. Acc. Chem. Res. 32:127-136.

Campbell, W., M. A. Drake, and D. K. Larick. 2003. The impact of fortification with conjugated linoleic acid (CLA) on the quality of fluid milk. J. Dairy Sci. 86:43-51.

Destaillats, F., C. Japiot, P. Y. Chouinard, J. Arul, and P. Angers. 2005. Rearrangement of rumenic acid in ruminant fats: A marker of thermal treatment. J. Dairy Sci. 88:1631-1635.

Dhiman, T. R., E. D. Helmink, D. J. McMahon, R. L. Fife, and M. W. Pariza. 1999. Conjugated linoleic acid content of milk and cheese from cows fed extruded oilseeds. J. Dairy Sci. 82:412-419.

Fritsche, J., R. Rickert, and H. Steinhart. 1999. Formation, contents, and estimation of daily intake of conjugated linoleic acid isomers 
and trans-fatty acids in foods. Pages 378-396 in Advances in Conjugated Linoleic Acid Research. Volume 1. J. L. Sébédio, W. W. Christie, and R. Adolf, ed. AOCS Press, Champaign, IL.

Gaullier, J. M., J. Halse, K. Hoye, K. Kristiansen, H. Fagertun, H. Vik, and O. Gudmundsen. 2004. Conjugated linoleic acid supplementation for 1 year reduces body fat mass in healthy overweight humans. Am. J. Clin. Nutr. 79:1118-1125.

Gnädig, S., and J. L. Sébédio. 2002. Relation between CLA contents in milk and in ripened cheese. XXVI IDF World Dairy Congress, Paris, France.

Herzallah, S. M., M. A. Humeid, and K. M. Al-Ismail. 2005. Effect of heating and processing methods of milk and dairy products on conjugated linoleic acid and trans fatty acid isomer content. J. Dairy Sci. 88:1301-1310.

International Organization for Standardization (ISO)-International Dairy Federation (IDF). 2001. Milk and milk products-Extraction methods for lipids and liposoluble compounds. International Standard ISO 14156-IDF 172:2001. IDF, Brussels, Belgium.

International Organization for Standardization (ISO)-International Dairy Federation (IDF). 2002. Milk fat-Preparation of fatty acid methyl esters. International Standard ISO 15884-IDF 182:2002. IDF, Brussels, Belgium.

Ip, C., S. P. Briggs, A. D. Haegele, H. J. Thompson, J. Storkson, and J. A. Scimeca. 1996. The efficacy of conjugated linoleic acid in mammary cancer prevention is independent of the level or type of fat in the diet. Carcinogenesis 17:1045-1050.

Ip, C., Y. Dong, M. M. Ip, S. Banni, G. Carta, E. Angioni, E. Murru, S. Spada, M. P. Melis, and A. Saebo. 2002. Conjugated linoleic acid isomers and mammary cancer prevention. Nutr. Cancer 43:52-58.

Ip, C., H. J. Thompson, and J. A. Scimeca. 1994. Conjugated linoleic acid suppresses mammary carcinogenesis and proliferative activity of the mammary gland in the rat. Cancer Res. 54:1212-1215.

Juanéda, P., S. B. de la Perriere, J. L. Sébédio, and S. Gregoire. 2003. Influence of heat and refining on formation of CLA isomers in sunflower oil. J. Am. Oil. Chem. Soc. 80:937-940.

Kamphuis, M. M. J. W., M. P. G. M. Lejeune, W. H. M. Saris, and M. S. Westerterp-Plantenga. 2003. The effect of conjugated linoleic acid supplementation after weight loss on body weight regain, body composition, and resting metabolic rate in overweight subjects. Int. J. Obes. 27:840-847.

Khanal, R. C. 2004. Potential health benefits of conjugated linoleic acid (CLA): A review. Asian-australas. J. Anim. Sci. 17:13151328.

Khanal, R. C., and K. C. Olson. 2004. Factors affecting CLA content in milk, meat, and egg: A review. Pakistan. J. Nutr. 3:82-98.

Lavillonière, F., J. C. Martin, P. Bougnoux, and J. L. Sébédio. 1998. Analysis of conjugated linoleic acid isomers and content in French cheeses. J. Am. Oil Chem. Soc. 75:343-352.

Luna, P., M. A. de la Fuente, and M. Juarez. 2005c. CLA unprocessed cheeses during the manufacturing stages. J. Agric. Food Chem. 53:2690-2695.

Luna, P., J. Fontecha, M. Juárez, and M. A. de la Fuente. 2005a. Conjugated linoleic acid in ewe milk fat. J. Dairy Res. 72:1-10.

Luna, P., J. Fontecha, M. Juárez, and M. A. de la Fuente. 2005b. Effects of a diet supplemented with linseed on the CLA content in ewe's milk fat. Lipids 40:445-454.

Ma, D. W. L., A. A. Wierzbicki, C. J. Field, and M. T. Clandinin. 1999. Conjugated linoleic acid in Canadian dairy and beef products. J. Agric. Food Chem. 47:1956-1960.

Malpuech-Brugere, C., W. P. H. G. Verboeket-van de Venne, R. P. Mensink, M. A. Arnal, B. Morio, M. Brandolini, A. Saebo, T. S.
Lassel, J. M. Chardigny, J. L. Sébédio, and B. Beaufrere. 2004. Effects of two conjugated linoleic acid isomers on body fat mass in overweight humans. Obes. Res. 12:591-598.

Masso-Welch, P. A., D. Zangani, C. Ip, M. M. Vaughan, S. F. Shoemaker, S. O. McGee, and M. M. Ip. 2004. Isomers of conjugated linoleic acid differ in their effects on angiogenesis and survival of mouse mammary adipose vasculature. J. Nutr. 134:299-307.

Masso-Welch, P. A., D. Zangani, C. Ip, M. M. Vaughan, S. Shoemaker, R. A. Ramirez, and M. M. Ip. 2002. Inhibition of angiogenesis by the cancer chemopreventive agent conjugated linoleic acid. Cancer Res. 62:4383-4389.

McGuire, M. K., Y. S. Park, T. D. Shultz, L. Y. Harrison, and M. A. McGuire. 1997. Conjugated linoleic acid concentrations of human milk and infant formula. Nutr. Res. 17:1277-1283.

Pariza, M. W. 2004. Perspective on the safety and effectivenes of conjugated linoleic acid. Am. J. Clin. Nutr. 79:1132-1136.

Parodi, P. W. 1977. Conjugated octadecadienoic acids of milk fat. J. Dairy Sci. 60:1550-1553.

Parodi, P. W. 2004. Milk fat in human nutrition. Aust. J. Dairy Technol. 59:3-59.

Precht, D., J. Molkentin, and M. Vahlendieck. 1999. Influence of the heating temperature on the fat composition of milk fat with emphasis on cis-/trans-isomerization. Nahrung 43:25-33.

Sæbø, A. 2003. Commercial synthesis of CLA. Pages 71-81 in Advances in Conjugated Linoleic Acid Research. Volume 2. J. L. Sébédio, W. W. Christie and R. Adlof, ed. AOCS Press, Champaign, IL.

Sehat, N., J. K. G. Kramer, M. M. Mossoba, M. P. Yurawecz, J. A. G. Roach, K. Eulitz, K. M. Morehouse, and Y. Ku. 1998. Identification of conjugated linoleic acid isomers in cheese by gas chromatography, silver ion high performance liquid chromatography and mass spectral reconstructed ion profiles. Comparison of chromatographic elution sequences. Lipids 33:963-971.

Sehat, N., R. Rickert, M. M. Mossoba, J. K. G. Kramer, M. P. Yurawecz, J. A. G. Roach, R. O. Adlof, K. M. Morehouse, J. Fritsche, K. D. Eulitz, H. Steinhart, and K. Yuoh. 1999. Improved separation of conjugated fatty acid methyl esters by silver ion-highperfomance liquid chromatography. Lipids 34:407-413.

Shantha, N. C., L. N. Ram, J. O'Leary, C. L. Hicks, and E. A. Decker. 1995. Conjugated linoleic acid concentrations in dairy products as affected by processing and storage. J. Food Sci. 60:695-697.

Stanton, C., J. Murphy, E. McGrath, and R. Devery. 2003. Animal feeding strategies for conjugated linoleic acid enrichment of milk. Pages 123-145 in Advances in Conjugated Linoleic Acid Research. Volume 2. J. L. Sébédio, W. W. Christie, and R. Adlof, ed. AOCS Press, Champaign, IL.

Terpstra, A. H. 2004. Effect of conjugated linoleic acid on body composition and plasma lipids in humans: An overview of the literature. J. Clin. Nutr. 79:352-361.

Villeneuve, P., R. Lago, N. Barouh, B. Barea, G. Piombo, J. Y. Dupré, A. LeGuillou, and M. Pina. 2005. Production of CLA isomers by dehydration and isomerization of castor bean oil. J. Am. Oil Chem. Soc. 82:261-269.

Werner, S. A., L. O. Luedecke, and T. D. Shultz. 1992. Determination of conjugated linoleic acid content and isomer distribution in three Cheddar-type cheeses: Effects of cheese cultures, processing and aging. J. Agric. Food Chem. 40:1817-1821.

Xu, S., T. D. Boylston, and B. A. Glatz. 2005. Conjugated linoleic acid content and organoleptic attributes of fermented milk products produced with probiotic bacteria. J. Agric. Food Chem. 53:9064-9072. 